\title{
THE ANALYIS OF CELL PHONE USAGE AMONG MEDICAL STUDENTS IN UCMS, BHAIRAHAWA, NEPAL
}

Nisha Maddheshiya, ${ }^{1}$ Varun Rastogi, ${ }^{2}$ Vanita Gautam, ${ }^{3}$ Nishant $^{2}$

\begin{abstract}
INTRODUCTION

The smartphones have become an integral part of human life. It combines different sophisticated features that allow users to keep pictures, memories, personal information, correspondence, health and financial data in one place. The phones allow people to maintain continuous communication without interruption of their movements and distances. Smartphones and handheld devices (HHD) combine advanced computing capability, such as internet communication, information retrieval, video, e-commerce and other features, that makes the device one of the indispensable requirements for many people.
\end{abstract}

\section{MATERIAL AND METHODS}

The research work was carried out to understand and also find correlation between excess usage of cell phones and its impact on human health. The study incorporates structured questionnaire administered to 200 medical students of their knowledge with the data obtained and statistically analyzed during the course of the study.

\section{RESULTS}

Our findings indicated that students are influenced negatively by mobile phones because attention is focused on chatting, music, surfing, entertainment and movies neglecting their health that has an impact on their physical and psychological status, which directly relates to the duration of usage of phone.

\section{CONCLUSION}

Mobile phone is one of the technologies of present era. It has both positive and negative impact on society. However, addiction and huge reliance on cell phones carry risks on human development and health. The current study highlights potential risks that cell phones can cause to medical students and the negative impact it has on their health status.

KEYWORDS Cellphone, Human health, Handheld devices, SMS

1. Department of Oral Medicine \& Radiology, UCMS College of Dental Surgery, Bhairahawa, Nepal

2. Department of Oral \& Maxillofacial Pathology, UCMS College of Dental Surgery, Bhairahawa, Nepal

3. Department of Conservative Dentistry \& Endodntics, UCMS College of Dental Surgery, Bhairahawa, Nepal

DOI: http//doi.org/10.3126/jucms.v7i2.27141

\author{
For Correspondence \\ Dr. Varun Rastogi \\ Department of Oral \& Maxillofacial Pathology \\ UCMS College of Dental Surgery \\ Bhairahawa, Nepal \\ Email: drvarunrastogi@gmail.com
}




\section{INTRODUCTION}

The smartphone is a cell phone that includes additional software functions such as an e-mail or an Internet browser and the word 'mobile' was in connotation with the Latin phrase "mobile vulgus" meaning excitable crowd. The use of smartphones has become an integral part of human's life. ${ }^{1}$ It combines different sophisticated features that allows users to keep pictures, memories, personal information, correspondence, health and financial data at one place and basically used for wireless communication. Smartphones and handheld devices (HHD) combine advanced computing capability, such as internet communication, information retrieval, video, e-commerce and other features, that makes the device one of the current indispensable tool.

According to Kevin Kimberlin, it's the fastest growing man made phenomenon ever from zero to 7.2 billion in three decades. $^{2}$ The introduction of new sense of speed and connectivity, it has made it universal globally. ${ }^{3}$ It utilizes electromagnetic radiations that are hazardous and its prolonged use can affect the human body. ${ }^{4,5}$

With the rapid evolving mobile phone technology, it has triggered an alarming situation for the normal functioning of the biological systems of the human body. The radiations emitted from the mobile phone utilize the frequency range from $3 \mathrm{KHz}$ to $300 \mathrm{GHz}$, which can penetrate in the body and affect the cell structure and DNA leading to series of reported health hazards such as brain cancer, Alzheimer's disease, Parkinson's disease, hormone and sleep disruption, DNA damage, male infertility, hearing impairment, asthma, hypertension, leukemia, congenital defects and rheumatoid Arthritis. ${ }^{6,7}$ The present study was done to study the attitude of students towards cell phones, their usage patterns, the way the students relate to the functionality (various features) of cell phones and their perceptions for issues related to medical side effects. The study may emphasize on health education among student's community.

\section{MATERIALAND METHODS}

The study was conducted at Universal College of Medical Sciences (UCMS), Bhairahawa, Nepal and was based on structured questionnaire. The study was conducted between 21/9/2019 and 04/10/2019 and ethical clearance was also taken from the institute. The data was collected from medical and dental college students. The questionnaire consists of 10 questions which cover adequate information regarding the duration, frequency of use and the consequences of excessive use of mobile phones such as discomfort, pain, headache, fatigue. Close ended questions were implemented which provided answers that are easy to interpret and analyze.
Sampling: The questionnaire was given to 200 medical and dental students to understand the influence of mobile phone on the health. The strata of the students (medical and dental) were made from each year and they were randomly selected for the study. Stratified random sampling method was used for data collection. The distribution of the population was normally distributed.

Statistical analysis: Percentage analysis using SPSS version 20 was done in the study to calculate the data obtained from the questionnaire that were given to the medical and dental students.

\section{RESULTS}

Regarding the time spend on mobile phone, 7.54\% students said that they spend one hour on mobile followed by $49.08 \%$ students responded with between 2-4 hours, 26.4\% responded with between $5-7$ hours/ day, $16.98 \%$ responded with for more than seven hours (Figure 1a).

The study reveals that the majority of students utilize mobile phones for surfing (39.7\%) followed by entertainment purposes $(30.06 \%)$ as shown in Figure $1 \mathrm{~b}$, besides voice calling and messaging (Figure 1d - 2b).

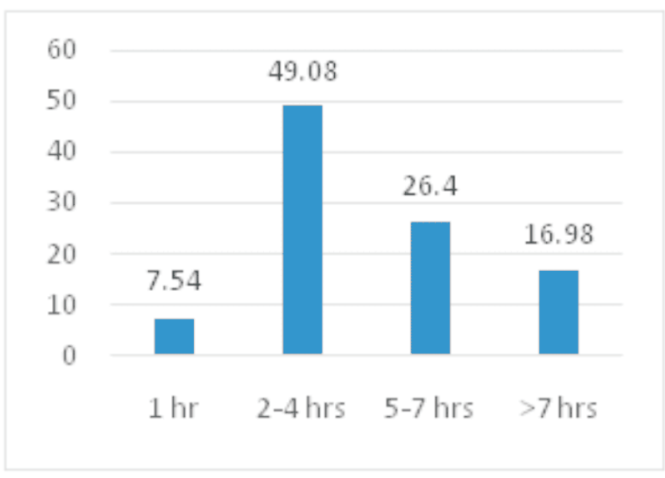

Figure 1a. Frequency and distribution of mobile use

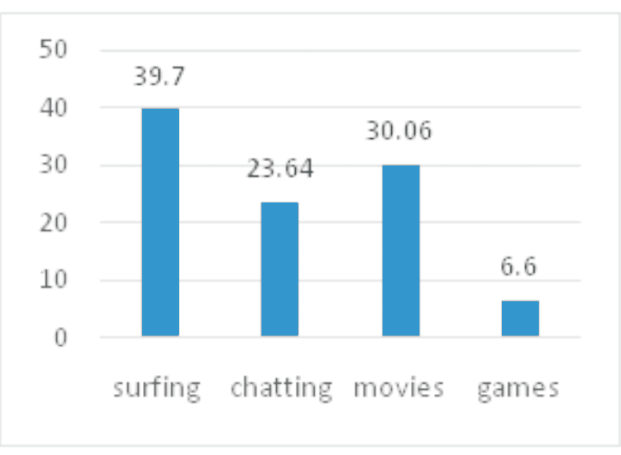

Figure $1 \mathrm{~b}$. Use of mobile phone 


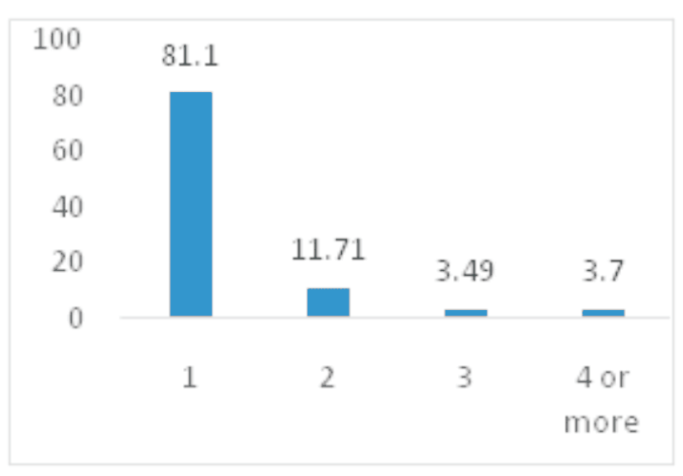

Figure 1c. Number of mobile phones

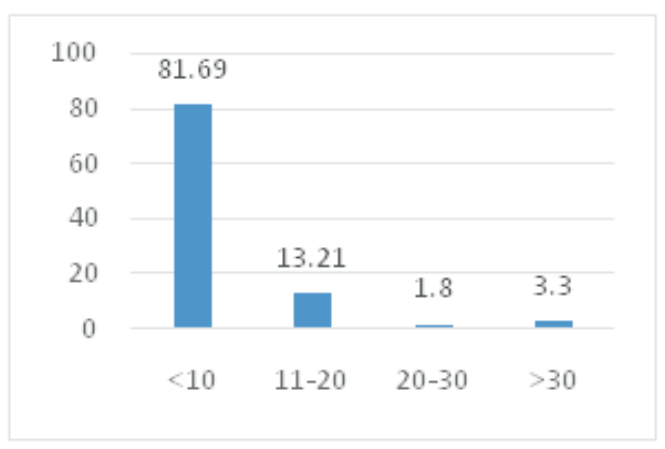

Figure $1 \mathrm{~d}$. Number of calls/ day

Figure 1c reveals number of mobile phones a student has, and $81.1 \%$ of the students have one phone followed by $11.71 \%$ have two phones, $3.49 \%$ having three phones, and $3.7 \%$ students have more than four phones.

Figure 1d reveals number of calls/ days a student receives, and $81.69 \%$ students receive less than 10 calls/ day followed by $13.21 \%$ receive $11-20$ calls/ day, $1.8 \%$ students receive $20-30$ calls/ day and $3.3 \%$ receive $>30$ calls/ day.

Figure 2 a reveals duration of calls/ day a student spent on mobile, and $80.01 \%$ students spend $<20 \mathrm{~min}$ per call/ day followed by $15.09 \%$ spend $25-50 \mathrm{~min}$ per call/ day, $1.7 \%$ students spend $50-100 \mathrm{~min}$ per call/day and $3.2 \%$ spend $>100$ min per call/day.

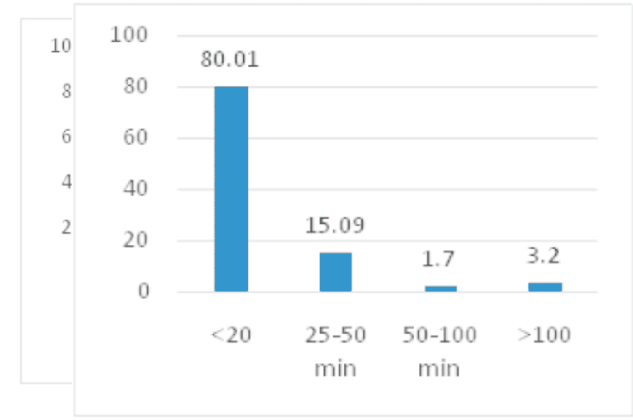

Figure 2a.Duration of calls/ day

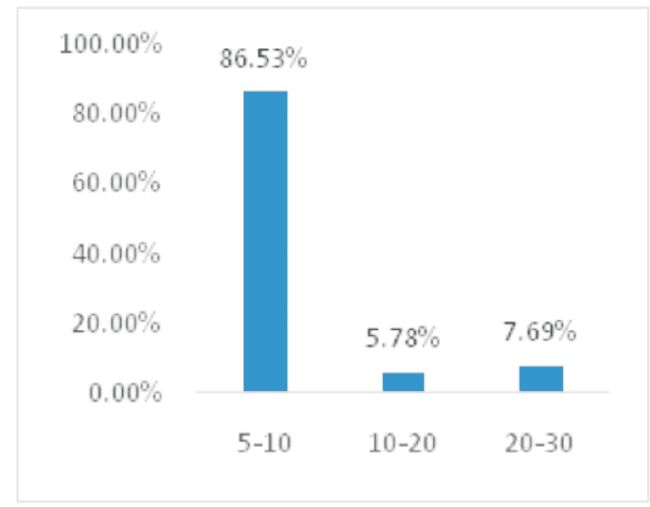

\section{Figure 2d. No. of SMS/ day}

Figure $2 \mathrm{~b}$ reveals number of SMS/ days a student receives, and $86.53 \%$ students receive 5-10 SMS/ day followed by $5.78 \%$ students reported that they receive 10-20 SMS/ day and 7.69\% receive 20-30 SMS/ day.

Figure 3 a shows the mode in which the mobile phone is maximum used by the students and $76.92 \%$ use mobile phone in hand held mode followed by $21.16 \%$ used ear phones, $1.92 \%$ used speaker.

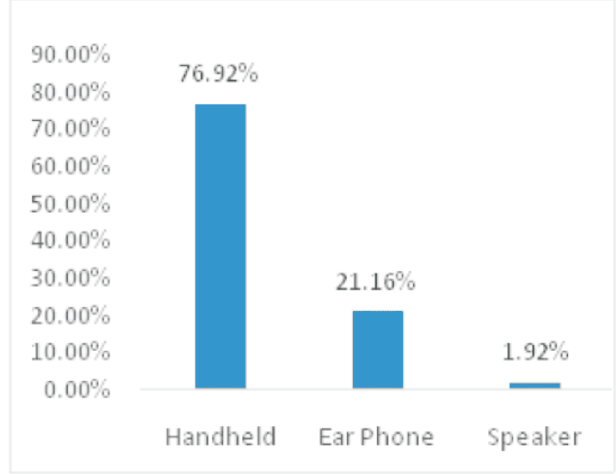

Figure 3a. Mode of mobile use

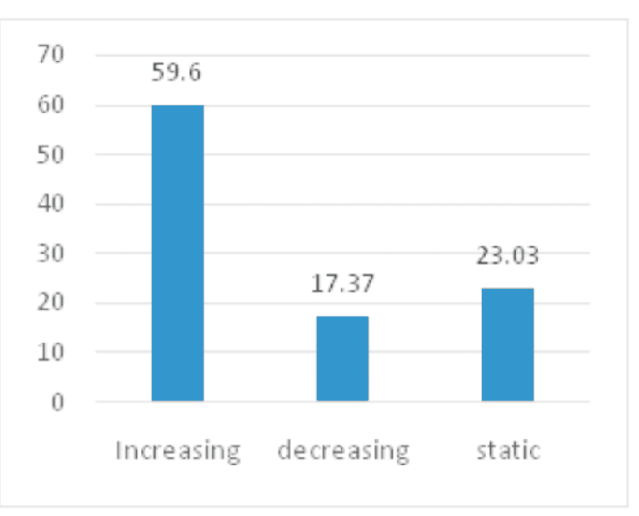

Figure $3 \mathrm{~b}$. Trend of mobile use

Figure $3 \mathrm{~b}$ shows the latest trend of the mobile phone usage 
among the students in terms of increasing, decreasing or static, and $59.6 \%$ reported the trend is increasing followed by $17.37 \%$ reported the trend is decreasing and $23.03 \%$ reported the trend is static.

Figure 4a shows the presence or absence of symptoms associated with excessive mobile use, and $65.38 \%$ students reported presence of symptoms and $34.62 \%$ students reported absence of symptoms.

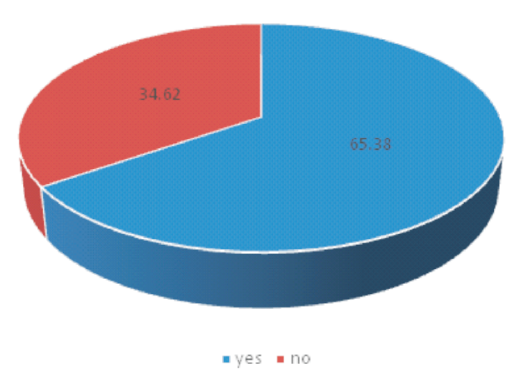

\section{Figure 4a. Symptoms of excessive mobile use}

Figure $4 \mathrm{~b}$ shows the correlation of duration of mobile use and symptoms associated with it, and 55\% students reported pain when using mobile phone for 2-4 hours followed by $25 \%$ students reported discomfort when using mobile phone for 5-7 hours and $20 \%$ students reported fatigue or headache when using mobile phone for greater than 7 hours.

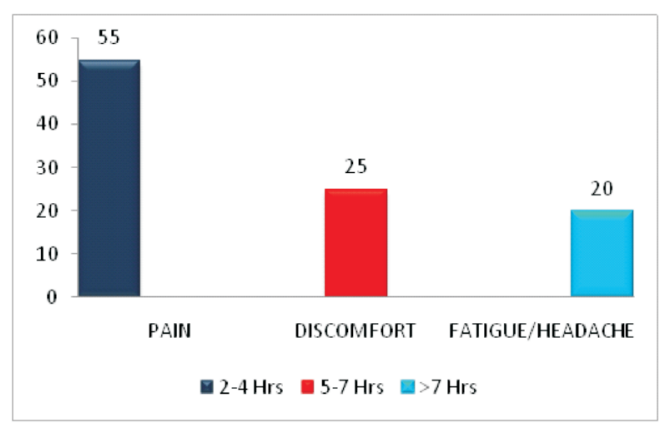

Figure $4 \mathrm{~b}$. Correlation of duration of mobile use and symptoms

\section{DISCUSSION}

Today, the cell phone is altering the life style of the people in the society. Even the people with low income are adapting mobile phones as tools to magnify their business. ${ }^{8}$ These devices help people to expand their life standards and, also let access to information, services, education and communication for free or for an affordable price, thus allowing the people to take control of their future. The handheld devices alter the way people interact with one another, access basic health, and education, financial and business services.
The presence of more advanced features in a mobile phone has led to its popularity and increased demand. The study done by Li et al (2012) $)^{3}$, Ilechukwu (2013) ${ }^{9}$ and Nwogu et al (2014) ${ }^{10}$ concluded that the greater the number of features on a mobile phone, the higher the behavioral intention to use the device for communication, thereby neglecting their health. Various studies have shown the correlation between duration of mobile phone usage and physical state of the user's health. The study done by Chen and Katz (2009) ${ }^{11}$ found that the popularity of mobile phone may be due to the need of the student to communicate with their family. According to Baysal, Sahenk and Hazneci (2010) ${ }^{12}$ the popularity of mobile phone was due to the features such as voice calling, SMS, live chat, music and entertainment, playing video games and online shopping, thus increasing the addiction for longer duration hence neglecting the health. This was similar to our study that the students are influenced to a greater extent by mobile phone for chatting (23.64\%), surfing (39.7\%), music, entertainment and movies (30.06\%), that has an impact on their physical and psychological status which directly relates to the duration of usage of phone.

Some studies have reported that the users complain of headache, hand tremors, pain in the fingers, shoulders and discomfort in the fingers. The research conducted by Berolo $(2005)^{2}$ revealed that the users complain of discomfort in one area of upper extremities, back or neck and long-term usage of the mobile causes additional tension on the tendons and muscles. The similar results were also seen by the research conducted by the Korean scientist. ${ }^{2}$ The study conducted by MACRO (the market analysis and consumer research organization) in $2004^{8}$ revealed that there is greater perception of medical side effects among the mobile users as compared to non-mobile users. The study conducted by Bandura (1986), Johnson and Payne (1985) and Rajan Balakrishnan and Elanchezhian Chinnavan ${ }^{8}$ showed that greater the product features and its complexity, more consumer effort needed ${ }^{12}$ and the diversity of the functions leads to stronger attachment of the user to the device. The extensive usage leads to health hazards that have been reported such as emotional misbalance and physical problems which is in concordance with our study. The study concluded that excessive use of mobile phone leads to pain in hands and fingers (55\%) followed by discomfort in ear, fingers and shoulder (25\%) and headache/ fatigue (20\%).

The study conducted by Sales Force Marketing Cloud (2014) (13 $^{13}$ reported that people between the ages 18-25 on an average, utilize phones for 5.2 hours/ day. The majority of the students in our study fall within the age category and $26.4 \%$ students use the phone for 5-7 hours/ day. This is same with our study which shows that $13.21 \%$ students receive $11-20$ calls/ day and $15.09 \%$ spent $25-50$ minutes per call/ day. The extended use of the mobile phone in the study suggests increasing 
addiction and dependency towards the mobile phone among medical and dental students.

SMS (Short Messaging Services) has been recognized as a new kind of contact, opening a channel, which has been described as being somewhere between making a call, sending an E-mail and making no contact at all. ${ }^{8}$ According to Bianchi and Philips $(2005)^{14}$, there is greater usage of SMS function and other features on mobile phones that has led to less face to - face interactions, shyness and loneliness and a leading cause of depression in the long run. The study conducted by MACRO (the market analysis and consumer research organization) in $2004^{8}$ revealed that making local calls and text SMS are more common activities, whereas other hand activities like sending picture messages, downloading or forwarding ring tones, getting new updates were seen less frequently. Similarly, this was consistent with our study which showed that $5.78 \%$ students reported that they receive 10-20 SMS/ day followed by $7.69 \%$ that they receive $20-30 \mathrm{SMS} /$ day.

The study conducted by Pew Research Center, showed that the mania has intensified to a full-blown obsession where people work, sleep, walk, talk and drive with their cell phones. The extensive use of cell phone exposes the user to the harmful radiations that has an impact not only on the physical health but on the psychological health as well. ${ }^{15,16}$ This is in concordance with our study which showed that $3.7 \%$ students have more than four phones followed by $3.49 \%$ having three phones. The increased number of the phones has led to its more addiction, hampering the health due to the emitted harmful phone radiation. The study suggests psychological dependency on mobile phones and to avoid health hazard among students, the use of mobile phone be restricted.

\section{CONCLUSION}

Steven Spielberg said "Technology can be our best friend, and technology can also be the biggest party pooper of our lives. It interrupts our story, interrupts our ability to have a thought or a daydream, to imagine something wonderful, because we're too busy bridging the walk from the cafeteria back to the office on the cell phone". Mobile phone is one of the technologies of our time. It has both positive and negative impact on own society. There is no one single opinion if cellphones bring harm to human's health. However, addiction and huge reliance on cell phones carry some risks on human development and health. The risks are emotional, physical, social and psychological. Saurabh Sharma noted, "A smartphone is an etoy designed for the lonely inner child hidden in each and every one of us". By conducting this research, the authors tried to bring attention to potential risks that cell phones can cause to the users and students are also influenced to a great extent by the social media negatively. It is advised that one should keep away from the excess use of mobile phone or decrease its usage as low as possible.

\section{ACKNOWLEDGEMENT}

We would like to thank Dr Anand Kumar, Principal, UCMS for guiding, mentoring and giving valuable suggestions for this study.

We would like to thank Mr. Pradeep Chhetri, Biostatistician Department of Community Medicine, UCMS for helping us in making statistical analysis for our study.

We would also like to thank the interns Ravi Kumar Deo, Safalta Deuja, Shiva Sigdel, Tanka Neupane and Tara Tiwari for helping us in compiling the data for the study.

\section{CONFLICT OF INTEREST}

The authors declare that there is no conflict of interest regarding the publication of this article.

\section{REFERENCES}

1. Ellis H Marconi 1889: Masculinity and the heroic age of science: wireless telegraphy at the British Association meeting at Dover in Hist Technol; 32: 120-136.

2. Miakotko L. The impact of smartphones and mobile devices on human health and life. http://www.nyu.edu/classes /keefer/wale/miakotkol. pdf 2017; 2-24.

3. Li B, Yang J, Song X and Lu B: Survey on disposal behavior and awareness of mobile phones in Chinese university students. Procedia Environmental Sciences. 2012;16: 469-476.

4. Skiba D.J. 2014: The connected age: Mobile apps and consumer engagement. Nursing Education Perspectives. 2014;35(3):199201.

5. Ahonen M 2007: Wireless system and Health risk implications for Educational and Pedagogical Practice.

6. Suhag AK, Larik RSA, Mangi GZ, et al. Impact of excessive mobile phone usage on human. Journal of Computer Science \& Systems Biology. 2016;9(6): 173 -177.

7. Sage C and Carpenter DO 2009: Public health implications of wireless technologies. Pathophysiology. 2009;16: 233-246.

8. MACRO Market Analysis and Consumer Research Organization 2004: A report on study of mobile phone usage among the Teenagers and Youth in Mumbai; 1-39.

9. Ilechukwu LC, The assessment of utilization of e learning opportunities for effective teaching and learning of religion in Nigerian tertiary institutions. European Journal of Educational Studies. 2013;5(3): 343-359.

10. Nwogu et al 2014: Towards utilization of e learning in preparing 
business education students for the world of work. African Education Review. 2014; 8(3): 155-164.

11. Chen Y.F. and Katz JE, Extending family to school life: College students use of the mobile phone. International Journal of Human Computer Studies. 2009; 67(2):179-191.

12. Baysal ZN et al 2010: Evaluation of the primary school level student's attitudes towards mobile phones. Procedia Social and Behavioral Sciences. 2010; 2: 4279-4284.

13. Shiva $\mathrm{H}$, Chinyamurindi $\mathrm{W}$ and Somdyala A. An investigation into the usage of mobile phones among technical and vocational educational and training students in South Africa. South African Journal of Information Management. 2016;18(1):1-8.

14. Bianchi A \& Philips J.G. 2005: Psychological predictors pf problem mobile phone use. Journal of Cyber Psychology \& Behaviour. 2005; 8 (1):39-51.

15. Khudnitskii et al 1998: On the evaluation of the influence of cellular phones on their users. Med Tr Prom Ekol.1998; 9: 20-24.

16. Kellenyi et al. Effects of mobile GSM radiotelephone exposure on the auditory brainstem response (ABR). Neurobiology. 1999; 7:79-81. 